\title{
Features of nitrogen metabolism in fishes
}

\author{
S. I. Dolomatov • P. V. Shekk • W. Zukow • \\ M. I. Kryukova
}

Received: 16 February 2011/Accepted: 28 March 2011/Published online: 7 April 2011

(C) The Author(s) 2011. This article is published with open access at Springerlink.com

\begin{abstract}
Presence in water is easily metabolized nitrogen-containing substances is a vital condition for the existence of food organisms in ponds used for fish reproduction. At the same time, the end products of nitrogen metabolism-ammonia, nitrites and nitrates are always displayed the body of fish into the environment, adding to the total number of these compounds dissolved in water. Ammonia, nitrite and nitrate anions are formed during biological processes, as well as man-made origin, have toxic properties and are considered as environmental factors that may limit fish productivity of reservoirs. The results of a brief review of the literature showed that the features of nitrogen metabolism in fish are actual direction of research, both theoretical science and in practical fish farming. Published the results of studies of amino acid metabolism in fish suggest that, firstly, the processes responsible for the neutralization and the release of ammonia from the body of fish, as well as ontogenetic aspects of the dynamics of formation and emission of ammonia is not fully understood. Meanwhile, several authors
\end{abstract}

S. I. Dolomatov · P. V. Shekk · M. I. Kryukova

Odessa State Environmental University, Odessa, Ukraine

W. Zukow $(\bowtie)$

Radom University, Radom, Poland

e-mail: w.zukow@wp.pl stressed the importance of this area of interest for the formation of science-based ways to improve the efficiency of plant breeding in fish culture. Secondly, endogenous nitrite, being the product of oxidation of the molecule nitric oxide and its transport form, the norm are always present in fish. However, the mechanisms responsible for maintaining the stability of the concentration of nitrite in the internal environment of fish, not well understood. Also, in our opinion, of interest to determine the physiological rules of nitrites and nitrates in the body of various species, depending on the seasons and stages of ontogeny. Thirdly, the literature pays much attention to the toxic properties of nitrite in water biocenosis. Certainly, the analysis of the manifestation in fish tissue-specific toxic effects of nitrites and their derivatives-an important area of research. Nevertheless, we can not exclude that it may be quite promising analysis of the incorporation of exogenous nitrite as a substrate exist in fish of the physiological mechanisms re-synthesis of nitric oxide. This kind of "interference" of endogenous and exogenous nitrite-anions are not causing serious structural damage to organs and tissues, however, can cause substantial damage to the practical fish farming, causing changes in the level of regulatory mechanisms of fish at the most critical stages: when working with manufacturers, the incubation of eggs, and larvae rearing and wintering fish.

Keywords Nitrogen · Metabolism · Fishes 


\section{Introduction}

Presence in water is easily metabolized nitrogencontaining substances is a vital condition for the existence of food organisms in ponds used for fish reproduction. At the same time, the end products of nitrogen metabolism-ammonia, nitrites and nitrates are always displayed the body of fish into the environment, adding to the total number of these compounds dissolved in water. Ammonia, nitrite and nitrate anions are formed during biological processes, as well as man-made origin, have toxic properties and are considered as environmental factors that may limit fish productivity of reservoirs.

It is known that zooplankton and phytoplankton, fish, and many other aquatic animals, in contrast to terrestrial organisms, are characterized by a high specific content of protein and free amino acids (Ostroumova 2001). According to figures released in the cited source, the natural feed for high nutritional requirements of fish in amino acids, due to severe plastic metabolism, primarily of young fish. On the other hand, in contrast to higher vertebrates, in fish amino acids are a major, and some species of fish core, substrate reactions of energy metabolism. The process of recycling of amino acids as an energy source, is preceded by deamination, during which the cleavage of the amino group with the formation of free ammonia. Power systems deamination of amino acids in fish illustrate the results of experimental studies that the rate of formation of endogenous ammonium in the cultured carp with closed cycle of water, greater than $4 \mathrm{~kg}$ per $1,000 \mathrm{~kg}$ of fish per day (Sim Do Thek 1991). In addition, data analysis pool of free amino acids in fish tissues confirmed a significant predominance of glutamic and aspartic acids (Ostroumova 2001), play a key role in the mechanisms of local neutralization and transport of highly toxic compounds-ammonia, formed during the deamination of amino acids (Wright et al. 2007).

The next object of our attention-nitrites and nitrates. Analyzing the metabolic pathways of nitrite and nitrate in fish, indicate that these compounds in small quantities are constantly present in the reservoirs used for fish reproduction, forming a natural way in the collapse of nitrogen-containing biological molecules, or enter the aquatic environment due to human pollution. The literature provides information about what is normal for the metabolic processes in fish contributes to the formation of the total pool of nitrite and nitrate reservoirs. The rate of formation of a fish endogenous hydrazoic and nitrate salts is lower than that of the ammonia when cultured carp with closed cycle of water, probably does not exceed $300 \mathrm{~g} / 1,000 \mathrm{~kg}$ of fish per day (Sim Do Thek 1991). Thus, in our opinion, the discussion metabolic pathways of nitrite and nitrate in the fish is expedient to distinguish two main blocks. First, the environmental aspect, devoted to studying the reaction of fish to nitrites and nitrates of exogenous origin, and, secondly, the metabolic pathways of endogenous nitrates and nitrites, including the sources of their formation, their physiological significance, as well as ways of removing the external environment.

Theoretical and practical importance of studying the mechanisms of clearance of ammonia in fish

The main end product of nitrogen metabolism in fish is ammonia secreted into the environment of specialized cell population gill apparatus (Evans et al. 2005). Ammonia output from the apical pole of the gill epithelium, rich in mitochondria (Evans DH et al. 2005; Wright and Wood Ch 2009). In the water, adding free protons of the ammonia molecule, on the one hand, lose the ability to back diffusion through the lipophilic environment of biological membranes, on the other hand, the conversion of ammonia into less toxic substance-ammonium cation maintains the concentration gradient of ammonia on the interface between the external and internal environment. The results of recent research underline the importance of the physiological role of the described mechanism, directly conjugated with the basic homeostatic functions of the gill apparatus, ensuring the stability of the parameters of gas exchange, acid-base and osmotic balance of internal environment (Evans et al. 2005). However, some authors ascertain the relevance of further research, whose aim is, firstly, the creation of adequate models of clearance of ammonia, which is closely associated with the work of the ion-transporting systems of gill epithelium (Wright and Wood Ch 2009), in- Second, the analysis of physiological and evolutionary aspects of the ways renal clearance of ammonia in fish (Nakada et al. 2007), as well as to study the features of neuro-humoral control systems of homeostatic functions of the gill apparatus of fish (Hoshijima and Hirose Sh 2007; Tse et al. 2007). 
In this case, considering the ammonium salt as the main end product of nitrogen metabolism in fish, some scholars emphasize the important scientific and practical value outlined above, the range of issues. In particular, the study of the effectiveness of glutamatedependent mechanisms intraorganic neutralize the ammonia in some species of fish, a long time can survive in arid environments where the gill system of clearance of nitrogenous products of catabolism are not fully functioning (Anderson et al. 2002), promotes the formation of science-based policy in selection of high-value fish species that are resistant to adverse hydrochemical conditions (Wright et al. 2007; Sanderson et al. 2010). In addition, attract the attention that the fish eggs, along with gill and kidney epithelium, characterized by high expression of specific transport proteins involved in mediated transport of ammonia (Nakada et al. 2007). From the position described in this review of the facts, understanding that the fertilized eggs is a powerful incentive not only anabolic potential but also the processes of energy metabolism, we can not exclude that the results of studies of the kinetics of transport of ammonia incubated eggs, may be of interest for the development of biomarkers, targeted for the selection of the most productive producers of fish.

Nitrites and nitrates, as the environmental factor of the aquatic environment

Many years of practical experience confirms the view that, in ponds used for fish reproduction levels of nitrites and nitrates in the water are subject to strict regulation, referring to the high toxicity of these compounds. Indeed, the results of recent research showing that a direct toxic effect of nitrite on fish organism most pronounced in the early stages of ontogeny, inducing a fish fry structural and functional disorders of the gill apparatus, an inflammation of muscle tissue (Kroupova et al. 2010). Perhaps the sensitivity of different fish species to the toxic effects of nitrite is due to physiological characteristics of the regulatory mechanisms of ion homeostasis, determining levels of income and accumulation of exogenous nitrite in fish (Jensen 2007). Along with this, some authors suggest that nitrite, which have high reactivity in aqueous media may be involved in the formation of complex compounds with other xenobiotics-polycyclic aromatic hydro- carbons (Wahidulla and Rajamanickam 2010). Studies conducted by the authors quoted a source, demonstrating that the reaction products nitrosation polycyclic aromatic hydrocarbons can vary extremely high cytotoxicity. In addition, the presence of small amounts of these complexes in natural waters can cause damage to genetic material of fish, as a possible cause of cancer.

Source, metabolism and physiological

significance of endogenous nitrates and nitrites

In the fish, as well as in higher vertebrates, the main precursor of endogenous nitrite and nitrate is a molecule of nitric oxide-NO (Hansen and Jensen 2010). In fish of NO has important regulatory functions, taking part in the management of the cardiovascular system (Hansen and Jensen 2010; Pedersen et al. 2010), the homeostatic functions of the gill apparatus (Jensen 2007; Cossins et al. 2009), the activity of the cytochrome electron transport chain of mitochondria (Jensen 2007), the reproductive system of fish (Tamanini et al. 2003; Tripathi and Krishna 2008). In turn, the process of NO synthesis is regulated by specific enzymatic complexes of NO-synthase, using as a substrate amino acid L-arginine. In this case, NO chemically unstable molecule, its life expectancy is measured by several tens of seconds. Directly in tissue NO is rapidly oxidized to nitrites and nitrates, which in turn can be used as substrates in the resynthesis NO, thus fulfilling the role of fish in the body of the transport form of nitric oxide (Jensen 2007). Basic physiological mechanisms of interconversion of $\mathrm{NO}$, nitrite and nitrate in the tissues of fish, in general, coincide with the views on the principles of the functioning cycle of nitric oxide, formulated for higher vertebrates (Reutov et al. 1994). The results of recent research show that the intensity of fish nitrite (nitrate)-reductase contour cycle of nitric oxide synthesis may sharply increase in oxygen deficiency (Pedersen et al. 2010). It has been suggested that a lack of oxygen stimulates the organ-and species-specific ways to utilize endogenous nitrites to their intracellular accumulation and a more rational use of nitrite reductase chain reaction (Hansen and Jensen 2010; Pedersen et al. 2010). In addition, the found experimental evidence suggested that exogenous nitrite in fish can also be included in the nitrite reductase circuit synthesis NO (Jensen 
2007). In the quoted source attracts the conclusion that the main channel of entry of exogenous nitrite in the body are the gills of fish, regulating the absorption of nitrite across the anion-transporting system of the gill epithelium. Possibly present in the fish-specific heme-containing proteins that perform the function of maintaining the balance of the activity of argininedependent nitrite (nitrate)-reductase contours nitrogen oxide cycle, determine the level of resistance of fish species to oxygen deficiency and the effectiveness of organ protection mechanisms against reperfusion injury (Cossins et al. 2009). In turn, the species-specific resistance of fish to high concentrations of exogenous nitrite (Jensen 2007; Jensen and Rohde 2010) may depend on the intensity of the transport of mineral substances in the cells of the gill apparatus, the rate of accumulation of nitrite in the intracellular sector and the efficiency of hemoglobindependent resynthesis NO. In our opinion, should also be noted that the sharp surge in activity intraorganic arginine-dependent NO synthesis can cause growth intraorganic and systemic concentration of endogenous nitrite in fish. In particular, at certain stages of maturation of oocytes recorded a significant increase in the concentration of nitrite and nitrate anions in the tissues of the gonads and blood plasma of fish (Tripathi and Krishna 2008). The authors cited sources that the dynamics of concentrations of chemically stable metabolites of NO in the ovarian tissue of fishes, reaches a maximum phase previtellogenesis, however, sharply declining in the phase of vitellogenesis, on the one hand points to the important role of $\mathrm{NO}$ in the control of reproductive functions of fish, but with On the other hand, is quite reliable marker of oogenesis in fish. Note that the figures provided in this section, the data show that in fish metabolism of nitrite endogenous and exogenous origin is closely connected with the activity cycle of nitric oxide. The literature presents data on how processes occur metabolic clearance of NO, due to the oxidation of molecules in a chemically stable compound-nitrite and nitrate anions. The data, which reveal the specifics intraorgan mechanisms maintaining the balance of the activity of argininedependent nitrite (nitrate)-reductase of the contour cycle of nitric oxide. Experimentally confirmed the possibility of using fish of exogenous nitrite as substrates in reactions resynthesis NO. However, attention is drawn to the following pattern-the authors of most-cited publications recognize that normally the content in the extracellular fluid of fish physiologically active metabolites of NO-endogenous nitrite is constant (Jensen 2007; Tripathi and Krishna 2008; Cossins et al. 2009; Jensen and Rohde 2010). Taking note of the reasoned reviewed publications in the importance of the physiological role of nitrite to fish, the existence of specific mechanisms that determine their kinetics in the body, and narrow ranges of concentration in the extracellular fluid, it can be assumed that normally the level of nitrite is a physiological constant. However, the mechanisms responsible for maintaining the stability of their level, including not only the accumulation in tissues and conversion, but the selection of the body are small and, in our opinion, require deeper investigation.

\section{Conclusion}

The results of a brief review of the literature showed that the features of nitrogen metabolism in fish are actual direction of research, both theoretical science and in practical fish farming.

Published the results of studies of amino acid metabolism in fish suggest that, firstly, the processes responsible for the neutralization and the release of ammonia from the body of fish, as well as ontogenetic aspects of the dynamics of formation and emission of ammonia is not fully understood. Meanwhile, several authors stressed the importance of this area of interest for the formation of science-based ways to improve the efficiency of plant breeding in fish culture.

Secondly, endogenous nitrite, being the product of oxidation of the molecule nitric oxide and its transport form, the norm are always present in fish. However, the mechanisms responsible for maintaining the stability of the concentration of nitrite in the internal environment of fish, not well understood. Also, in our opinion, of interest to determine the physiological rules of nitrites and nitrates in the body of various species, depending on the seasons and stages of ontogeny.

Thirdly, the literature pays much attention to the toxic properties of nitrite in water biocenosis. Certainly, the analysis of the manifestation in fish tissuespecific toxic effects of nitrites and their derivativesan important area of research Nevertheless, we can not 
exclude that it may be quite promising analysis of the incorporation of exogenous nitrite as a substrate exist in fish of the physiological mechanisms re-synthesis of nitric oxide. This kind of "interference" of endogenous and exogenous nitrite-anions are not causing serious structural damage to organs and tissues, however, can cause substantial damage to the practical fish farming, causing changes in the level of regulatory mechanisms of fish at the most critical stages: when working with manufacturers, the incubation of eggs, and larvae rearing and wintering fish.

Open Access This article is distributed under the terms of the Creative Commons Attribution Noncommercial License which permits any noncommercial use, distribution, and reproduction in any medium, provided the original author(s) and source are credited.

\section{References}

Anderson PM, Broderius MA, Fong KC et al (2002) Glutamine synthetase expression in liver, muscle, stomach and intestine of Bostrichthys sinensis in response to exposure to a high exogenous ammonia concentration. J Exp Biol 205:2053-2065

Cossins AR, Williams DR, Foulkes NS et al (2009) Diverse cell-specific expression of myoglobin isoforms in brain, kidney, gill and liver of the hypoxia-tolerant carp and zebrafish. J Exp Biol 212:627-638

Evans DH, Piermarini PM, Choe KP (2005) The multifunctional fish gill: dominant site of gas exchange, osmoregulation, acid-base regulation, and excretion of nitrogenous waste. Physiol Rev 85:97-177

Hansen MN, Jensen FB (2010) Nitric oxide metabolites in goldfish under normoxic and hypoxic conditions. J Exp Biol 213:3593-3602

Hoshijima K, Sh Hirose (2007) Expression of endocrine genes in zebrafish larvae in response to environmental salinity. J Endocrinol 193:481-491

Jensen FB (2007) Nitric oxide formation from nitrite in zebrafish. J Exp Biol 210:3387-3394

Jensen FB, Rohde S (2010) Comparative analysis of nitrite uptake and hemoglobin-nitrite reactions in erythrocytes: sorting out uptake mechanisms and oxygenation dependencies. Am J Physiol Regul Integr Comp Physiol 298(N4):972-982

Kroupova H, Prokes M, Macova S et al (2010) Effect of nitrite on early-life stages of common carp (Cyprinus carpio L.). Environ Toxicol Chem 29(N3):535-540

Nakada T, Hoshijima K, Esaki M et al (2007) Localization of ammonia transporter Rhcg1 in mitochondrion-rich cells of yolk sac, gill, and kidney of zebrafish and its ionic strength-dependent expression. Am J Physiol Regul Integr Comp Physiol 293:R1743-R1753

Ostroumova YN (2001) Byolohycheskye osnovы kormlenyya rub.-Sankt-Peterburh: HosNYORX 372s

Pedersen CL, Faggiano S, Helbo S et al (2010) Roles of nitric oxide, nitrite and myoglobin on myocardial efficiency in trout (Oncorhynchus mykiss) and goldfish (Carassius auratus): implications for hypoxia tolerance. J Exp Biol 213:2755-2762

Reutov VP, Sorokina EG, Kaiushin LP (1994) The nitric oxide cycle in mammals and nitrite reducing activity of hemecontaining proteins. Vopr Med Khim (Mosc) 40(N6):31-35

Sanderson LA, WrightP A, RobinsonJ W et al (2010) Inhibition of glutamine synthetase during ammonia exposure in rainbow trout indicates a high reserve capacity to prevent brain ammonia toxicity. J Exp Biol 213:2343-2353

Sym Do Txek (1991) Praktycheskoe rukovodstvo po zavodskomu razvedenyyu sazana y karpa. M VNYRO 229s

Tamanini C, Basini G, Grasselli F, Tirelli M (2003) Nitric oxide and the ovary. J Anim Sci 81:E1-E7

Tripathi V, Krishna A (2008) Changes in nitric oxide (NO) synthase isoforms and $\mathrm{NO}$ in the ovary of Heteropneustes fossilis (Bloch.) during the reproductive cycle. J Endocrinol 199:307-316

Tse WK, Au DW, Wong ChK (2007) Effect of osmotic shrinkage and hormones on the expression of $\mathrm{Na}+\mathrm{H}+$ exchanger- 1 , $\mathrm{Na}+/ \mathrm{K}+/ 2 \mathrm{Cl}-$ cotransporter and $\mathrm{Na}+/ \mathrm{K}+$-ATPase in gill pavement cells of freshwater adapted Japanese eel, Anguilla japonica. J Exp Biol 210:2113-2120

Wahidulla S, Rajamanickam YR (2010) Detection of DNA damage in fish Oreochromis mossambicus induced by co-exposure to phenanthrene and nitrite by ESI-MS/MS. Environ Sci Pollut Res Int 17(N2):441-452

Wright PA, Wood Ch M (2009) A new paradigm for ammonia excretion in aquatic animals: role of Rhesus (Rh) glycoproteins. J Exp Biol 212:2303-2312

Wright PA, Steele SL, Huitema A, Bernier NJ (2007) Induction of four glutamine synthetase genes in brain of rainbow trout in response to elevated environmental ammonia. J Exp Biol 210:2905-2911 